\title{
DIAGNÓSTICO HIGIÊNICO-SANITÁRIO E DA QUALIDADE MICROBIOLÓGICA DE PRODUTOS LÁCTEOS EM UM LATICÍNIO LOCALIZADO EM TUCURUÍ-PARÁ
}

\section{Hygienic-sanitary diagnosis and microbiological evaluation of dairy products from a dairy industry located in Tucuruí - Pará}

\author{
Elaine Lopes Figueiredo ${ }^{1 *}$, Jéssica Kelly Lima Melo ${ }^{l}$, \\ Natália Caroline Oliveira Neves ${ }^{1}$
}

\begin{abstract}
RESUMO
Devido ao grande consumo de leite e derivados, torna-se imprescindível sua avaliação higiênico-sanitária e microbiológica, visando oferecer aos consumidores alimentos de qualidade. Este trabalho teve como objetivos avaliar o grau de adequação de um laticínio às Boas Práticas de Fabricação (BPF), identificar Pontos Críticos de Controle (PCC) e Pontos de Controle (PC) no processamento de leite pasteurizado e iogurte de morango; avaliar a qualidade microbiológica, bem como o índice de contaminação das superfícies de processamento em um laticínio localizado no município de Tucuruí - Pará. Na avaliação de BPF, utilizouse a Ficha de Verificação da Resolução de Diretoria Colegiada 275. Avaliou-se as etapas dos fluxogramas de fabricação dos derivados de leite para identificação dos $\mathrm{PCC}^{\prime}$ s e $\mathrm{PC}^{\prime}$ s e dos perigos potenciais à saúde dos consumidores. As análises microbiológicas dos produtos (coliformes totais e termotolerantes, contagem de Staphylococcus aureus e pesquisa de Salmonella) seguiram os métodos oficiais de American Public Health Association. Realizou-se também análises de swabs (coliformes totais e termotolerantes e contagem de Staphylococcus aureus) em doze superfícies envolvidas com o processamento dos produtos. Com base no grau de adequação às BPF, o laticínio enquadrou-se no Grupo 1. Constatou-se por meio das análises microbiológicas do leite pasteurizado e do iogurte conformidade com as exigências legais. Entretanto, embora as superfícies estivessem de acordo com as especificações para coliformes termotolerantes, constatou-se alto índice
\end{abstract}

1 Universidade do Estado do Pará, Travessa Perebebuí, 2623, Marco, 66087-670, Belém, PA, Brasil. E-mail: lane_figueiredo@yahoo.com.br

* Autor para correspondência. 
de contaminação das mesmas com Staphylococcus aureus e coliformes totais, indicativas de falhas higiênico-sanitárias no laticínio.

Palavras-chave: qualidade; boas práticas; derivado lácteo.

\begin{abstract}
This work evaluated the degree of compliance of a dairy industry in relation to Good Manufacturing Practice (GMP). The objectives were to identify the Critical Control Points (CCP) and Control Points (CP) in the pasteurized milk and strawberry yogurt processing chain; to evaluate the microbiological quality of the products, as well as the contamination index of the processing surfaces of a dairy industry located in the municipality of Tucuruí, Pará. Regarding the GMP evaluation, it was used the Collegiate Board Resolution 275 verification sheet. The steps of the flowcharts of the dairy products manufacturing chain were evaluated in order to identify PCCs and PCs and potential health hazards to the consumers. The microbiological analysis of the dairy products (total and thermo-tolerant coliforms, Staphylococcus aureus counts and Salmonela research) followed the official methods of the American Public Health Association. Also, swab of 12 surfaces involved in the processing chain of the products were submitted to the same microbiological analysis. Based on the degree of compliance with GMP, the dairy industry was placed within the Group 1 category. The results of microbiological analysis in pasteurized milk and yoghurt were found to comply with the legal requirements. However, although the surfaces were in accordance with the specifications for thermo-tolerant coliforms, a high contamination rate with Staphylococcus aureus and total coliforms were found, which indicates hygienic-sanitary failure in the dairy industry.
\end{abstract}

Keywords: good manufacturing practices; dairy products.

\section{INTRODUÇ̃̃O}

O leite contém muitos nutrientes essenciais para a dieta humana, além de constituir um excelente meio de cultura para a multiplicação de diversos microrganismos. Portanto, a implementação das Boas Práticas Agropecuárias (BPA) e Boas Práticas de Fabricação (BPF) são indispensáveis para garantir a boa qualidade da matéria-prima e, assim, obtenção de derivados do leite de acordo com os padrões de identidade e qualidade (FIGUEIREDO et al., 2010).

$\mathrm{Na}$ indústria de laticínios devem ser aplicadas tecnologias adequadas de fabricação dos produtos. Ao lado do aporte tecnológico representado, principalmente, pela adoção de práticas higiênicas, implementação de mudanças na área tecnológica da produção, métodos adequados de conservação e inovação na produção de derivados, as indústrias devem incorporar e tornar parte obrigatória o sistema de controle de qualidade.

As Boas Práticas de Fabricação (BPF), descritas na Portaria n ${ }^{\circ}$ 368/97, do Ministério da Agricultura, Pecuária e Abastecimento, MAPA, são definidas como o "conjunto de diretrizes, normas e procedimentos, exigidos na elaboração de produtos alimentícios industrializados para o consumo humano, cujo objetivo principal é assegurar que os produtos sejam sempre fabricados com a qualidade exigida, com ênfase na pureza e segurança" (BRASIL, 1997). Inclui requisitos de estrutura 
física e do pessoal envolvido no processo produtivo, além dos procedimentos de higiene do estabelecimento e cuidados sanitários, determinantes para a qualidade alimentícia.

O sistema Análise de Perigos e Pontos Críticos de Controle (APPCC) tem como objetivo de alinhar a gestão da qualidade com a elaboração de produtos isentos de defeitos, conforme prescrita pela norma ISO 9000. O APPCC consiste na gestão do controle da segurança dos alimentos em uma linha de produção, por meio da identificação dos Pontos Críticos de Controle (PCC), Pontos de Controle (PC), estabelecimento de limites críticos, sua monitoração, verificação e registro (PAS, 2015).

A implementação dos programas de qualidade BPF e do sistema APPCC pelas indústrias é uma exigência da legislação, dos mercados nacionais e internacionais, a fim de garantir a qualidade e inocuidade dos produtos lácteos e a saúde dos consumidores. Desta forma, a empresa tem a possibilidade de aumentar a sua competitividade e melhorar a sua estrutura organizacional interna. Pode-se assim oferecer produtos com qualidade higiênico-sanitária e microbiológica, de acordo com os padrões exigidos pela legislação para cada alimento.

Objetivou-se avaliar o grau de adequação de um laticínio às Boas Práticas de Fabricação (BPF), identificar os Pontos Críticos de Controle (PCC) e Pontos de Controle (PC) no processamento de leite pasteurizado e iogurte de morango e a sua qualidade microbiológica, bem como o índice de contaminação das superfícies de processamento em um laticínio localizado no município de Tucuruí, Pará.

\section{MATERIAL E MÉTODOS}

\section{Avaliação do atendimento aos requisitos de Boas Práticas de Fabricação - BPF}

Para a avaliação do atendimento ao programa BPF no laticínio utilizou-se a Ficha de Verificação (check-list) da Resolução de Diretoria Colegiada - RDC no 275, de 21/10/2002 (ANVISA, 2002), do Ministério da Saúde, que dispõe sobre o Regulamento Técnico de Procedimentos Operacionais $\mathrm{Pa}$ dronizados aplicados aos Estabelecimentos Produtores/Industrializadores de Alimentos e a Lista de Verificação de Boas Práticas de Fabricação em Estabelecimentos Produtores/ Industrializadores de Alimentos (ANVISA, 2002). Adotaram-se os padrões de conformidade de acordo com a RDC n 216 (ANVISA, 2004), que dispõe sobre o Regulamento Técnico de Boas Práticas para Serviços de Alimentação em Indústrias e Restaurantes.

O resultado da avaliação da Lista de Verificação foi obtido pela soma de todos os itens em conformidade e os itens em não conformidade com o BPF. Para os itens que obtiveram como resposta "SIM", foram atribuídos o valor um (1). Para os itens que obtiveram como resposta "NÃO", foram atribuídos o valor zero (0). As respostas SIM foram somadas e em seguida calculadas a percentagem de adequação. Para a realização deste cálculo foi realizada regra de três (3) para cada item correspondente do checklist (ANVISA, 2004). A partir desse cálculo (equação 1), os estabelecimentos foram agrupados de acordo com o percentual dos itens em conformidade: grupo 1: bom (76 a $100 \%$ de itens atendidos); grupo 2: regular (51 a $75 \%$ dos itens atendidos); grupo 3: ruim (0 a $50 \%$ dos itens atendidos) (ANVISA, 2004).

$$
X=\frac{\text { itens atendidos } \times 100}{\text { itens } j \text { julgados }}
$$

Equação 1 - grau de atendimento dos itens

Em que:

$\mathrm{X}=$ Porcentagem de adequação

Itens atendidos $=\mathrm{Sim}$

Itens julgados $=$ Sim e Não 
Identificação de Pontos Críticos de Controle (PCC) e Pontos de Controle (PC) nos fluxogramas de fabricação no leite pasteurizado e iogurte de morango

Fez-se a avaliação dos fluxogramas de fabricação do leite pasteurizado padronizado a 3\% de gordura e do iogurte sabor morango, por meio da análise de todas as suas etapas. Analisaram-se os perigos potenciais à saúde dos consumidores, com a identificação dos Pontos Críticos de Controle (PCC) e Pontos de Controle (PC), com a determinação das possíveis medidas preventivas para controlar os perigos (FAO/WHO, 2003).

\section{Análises microbiológicas do leite pasteu- rizado e do iogurte de morango}

Foram realizadas análises microbiológicas do leite pasteurizado padronizado a $3 \%$ de gordura e do iogurte sabor morango, produzidos no laticínio. As coletas foram realizadas em quatro dias diferentes para cada produto, para obtenção da uma média. Porções de $100 \mathrm{~mL}$ das amostras foram coletadas, separadamente e assepticamente, imediatamente após a sua fabricação. As amostras foram acondicionadas em caixas de material isotérmico contendo gelo, identificadas e enviadas ao Laboratório de Microbiologia do Centro de Ciências Naturais e Tecnologia (CCNT), da Universidade do Estado do Pará (UEPA). Foram realizadas as análises: coliformes totais, coliformes termotolerantes, contagem de Staphylococcus aureus e pesquisa de Salmonella spp., de acordo com métodos descritos pela American Public Health Association (APHA) (APHA, 2001).

\section{Avaliação microbiológica de superfícies de processamento}

Foram realizadas avaliações microbiológicas das superfícies de processamento. Empregou-se a técnica de coleta com swabs em doze superfícies: galão de transporte de leite, tanque de recepção de leite, esteira, bancada de embalagem do iogurte, tanque de elaboração do iogurte, faca, peneira, mesa de aço inoxidável utilizada para envase do iogurte, embalagem de iogurte e mãos de três manipuladores. Em cada superfície, foram realizadas quatro coletas por meio de swab, para obtenção da média.

Empregou-se swabs de algodão não absorventes, preparados de acordo com técnica descrita pela APHA (EVANCHO et al., 2001). A remoção de microrganismos da superfície foi feita com o swab esterilizado umedecido em solução peptonada $0,1 \%$. Friccionou-se o swab nas superfícies avaliadas em uma área de $10 \times 10 \mathrm{~cm}^{2}$ delimitada por um molde esterilizado. Para a coleta de amostras da superfície de mãos dos manipuladores, o swab foi friccionado a partir dos punhos, da parte inferior da palma até a extremidade dos dedos, retornando-se ao punho. Em seguida, os swabs contendo os microrganismos aderidos foram transferidos para tubos de ensaio, contendo $10 \mathrm{~mL}$ de tampão fosfato. Esses tubos foram transportados ao Laboratório de Microbiologia de Alimentos, do Centro de Ciência Naturais e Tecnologia (CCNT), da Universidade o Estado do Pará (UEPA). As análises microbiológicas realizadas foram: coliformes totais, coliformes termotolerantes e contagem de Staphylococcus aureus.

\section{RESULTADOS E DISCUSSÃO}

\section{Avaliação do programa de qualidade Boas Práticas de Fabricação - BPF}

O grau de atendimento dos itens de Boas Práticas de Fabricação (BPF) ficou na faixa de $76 \%$ a $100 \%$, portanto, enquadrado no Grupo 1 . O maior grau de adequação registrado (100\%) foi constatado para os itens "Controle de Qualidade do Produto Final" e "Documentação" e o menor grau foi observado para o item "Edificações e Instalações" (Tabela 1). 
As edificações e as instalações devem ser projetadas de forma a possibilitar um fluxo ordenado e sem cruzamentos em todas as etapas da preparação de alimentos e facilitar as operações (ANVISA, 2004). Os problemas observados neste item estavam relacionados com as portas, pisos, paredes e ventilação. Embora no laticínio tivesse portas com fechamento automático, uma dessas portas encontrava-se com defeito, o que poderia ser uma causa de contaminação, por meio das mãos de manipuladores. De acordo com a legislação vigente, as portas devem ter superfície lisa, não absorvente e, preferencialmente, possuir fechamento automático ou conter molas para evitar o manuseio. As mesmas devem permanecer fechadas e não ter comunicação com o ambiente de manipulação de alimentos (ANVISA, 2004).

Observou-se no piso a presença de alguns defeitos como rachaduras e trincas. De acordo com a RDC n 216 (ANVISA, 2004), os pisos devem ser de cores claras, lisos, antiderrapantes, impermeáveis, laváveis, de fácil higienização e resistentes a substâncias corrosivas. Ao avaliar as paredes, verificouse que eram de cores claras, revestidas, com acabamento liso, impermeável e de fácil higienização. Porém, observaram-se algumas rachaduras, infiltrações, e inexistência de ângulos abaulados entre as paredes e o piso e entre as paredes e tetos. A ventilação artificial e a circulação de ar não foi considerada sa- tisfatória, em função da grande quantidade de vapor quente em meio a produção dos alimentos.

Quanto à higienização da indústria, verificou-se que são utilizados sanitizantes à base de cloro, concentração de $400 \mathrm{mg} / \mathrm{L}$, para sanitização das garrafas e tampas de iogurte. A limpeza dos latões de transporte do leite é realizada com detergentes alcalinos e ácidos, respectivamente. A sanitização de utensílios como a picadeira, filadeira, moldadeira, mesas e prensas é realizada com detergente clorado, na concentração de $400 \mathrm{mg} / \mathrm{L}$, por 10 minutos.

O item "manipuladores" apresentou 92,57\% de adequação. A higienização das mãos é feita com sabonete bactericida e solução clorada. Na entrada da fábrica havia pé-de-lúvio, higienizador de mãos, papel toalha e lixeira com dispositivo de pedal. Porém, pode-se observar que nem todos os manipuladores efetuam a higiene das mãos frequentemente ao longo do dia, além de não realizarem a higienização nas trocas das atividades.

No que se refere ao item "produção e transporte de alimentos", a percentagem de adequação foi de $96,35 \%$. A recepção da matéria-prima, ingredientes e embalagem são realizadas adequadamente, em local apropriado e separado da área de processamento. A rotulagem e o armazenamento do produto final também estavam de acordo com o estabelecido no programa de qualidade, com

Tabela 1 - Percentual de atendimento do laticínio a requisitos de Boas Práticas de Fabricação (BPF)

\begin{tabular}{l|c|c|c}
\hline \multicolumn{1}{c|}{ Itens avaliados } & $\begin{array}{c}\text { Itens atendidos } \\
(\%)\end{array}$ & $\begin{array}{c}\text { Itens não atendidos } \\
(\%)\end{array}$ & Não aplicável \\
\hline Edificações e instalações & 81,84 & 18,16 & 5 \\
Equipamentos, móveis e utensílios & 89,47 & 10,53 & 1 \\
Manipuladores & 92,57 & 7,43 & - \\
Produção e transporte de alimentos & 96,35 & 3,65 & 1 \\
Controle de qualidade do produto final & 100 & 0 & - \\
Documentação & 100 & 0 & - \\
\hline
\end{tabular}


data de fabricação, data de validade e lote. $\mathrm{O}$ transporte era feito em caminhões refrigerados, sob temperatura média de $5^{\circ} \mathrm{C}$ a $7^{\circ} \mathrm{C}$.

\section{Identificação de Pontos Críticos de Con- trole (PCC) e Pontos de Controle (PC) nos fluxogramas de fabricação do leite pasteu- rizado e iogurte de morango}

No fluxograma (Figura 1) são apresentadas as etapas de processamento do leite pasteurizado, padronizado a 3\% de gordura, com a identificação dos Pontos Críticos de Controle (PCC) e dos Pontos de Controle (PC).

Os principais $\mathrm{PCC}^{\prime}$ s identificados no fluxograma foram: obtenção da matériaprima, transporte, recepção da matéria prima e pasteurização (Figura 1). A etapa de "obtenção da matéria-prima" foi considerada PCC, considerando a possibilidade de ocorrência de contaminação do leite com antibióticos e microrganismos patogênicos. Algumas medidas preventivas devem ser aplicadas como assistência técnica ao produtor, higiene da ordenha, controle de antibióticos no leite e avaliações microbiológicas.

O transporte da matéria-prima era realizado em caminhões tanque refrigerados, sob temperatura média de $7{ }^{\circ} \mathrm{C}$, com o leite cru acondicionado em galões de polietileno de 50 L. É necessário que se faça o controle da temperatura nos tanques, uma vez que pode ocorrer crescimento de microrganismos indesejáveis em caso de temperaturas mais altas que as recomendadas para conservação do leite. Pode ocorrer também a multiplicação de bactérias patogênicas, como Staphylococcus aureus, que está associado a falta de higienização nos utensílios e nos caminhões-tanque que fazem o transporte. Algumas medidas preventivas podem melhorar a qualidade do leite como reduzir o tempo de transporte entre a ordenha e a recepção no laticínio e higienizar corretamente os latões e caminhões-tanque.

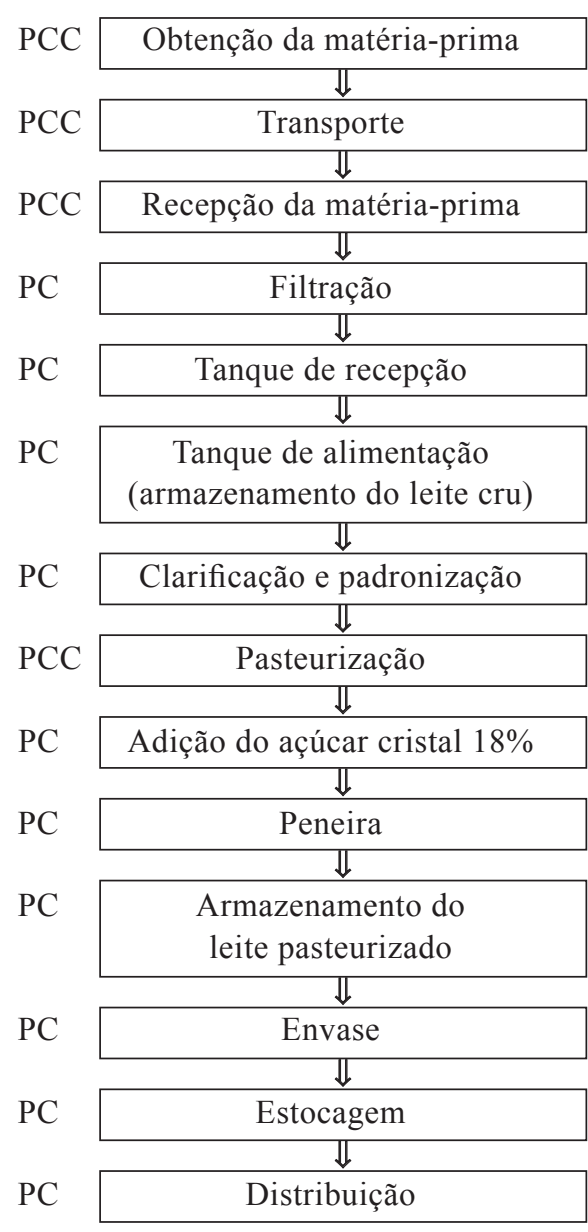

Figura 1 - Fluxograma de processamento do leite pasteurizado padronizado a $3 \%$ de gordura

$\mathrm{Na}$ recepção do leite também existem riscos de ocorrência de perigos de natureza química. Após esta etapa não há nenhuma ação possível para evitar, eliminar ou diminuir o perigo, sendo assim considerada PCC. Se a pasteurização não for realizada de forma eficiente, alguns microrganismos patogênicos podem sobreviver. É necessário que se faça o controle adequado do binômio tempo/temperatura. Como medidas preventivas têm-se a manutenção, limpeza e manipulação 
correta do pasteurizador, funcionamento correto da válvula de desvio de fluxo, monitoramento contínuo de tempo e temperatura e testes das enzimas fosfatase e peroxidase, as quais são relevantes para a qualidade do produto.

Os principais $\mathrm{PC}^{\prime} \mathrm{s}$ identificados foram: recepção da matéria-prima, filtração, tanque de recepção, tanque de alimentação, clarificação e padronização, adição do açúcar, peneira, armazenamento do leite, envase, estocagem e distribuição.

A clarificação tem como objetivo remover perigos de natureza física. O controle é feito por meio do monitoramento por inspeção visual, higienização diária e manutenção dos filtros (disco da centrifuga). No que se refere à padronização do leite, o estabelecido para o teor de gordura do leite pasteurizado é de 3\%. Faz-se necessário o controle e avaliação deste teor de gordura para assim manter o produto de acordo com o padrão legal.

No fluxograma a seguir (Figura 2) apresentam-se as etapas de elaboração do iogurte sabor morango, com a identificação dos Pontos Críticos de Controle (PCC) e dos Pontos de Controle (PC).

Os principais $\mathrm{PCC}^{\prime}$ s identificados no fluxograma foram: leite pasteurizado a $3 \%$ de gordura, tratamento térmico a $90{ }^{\circ} \mathrm{C}$ e fermentação. A etapa de adição do "leite pasteurizado a $3 \%$ de gordura" foi considerada PCC considerando a possibilidade de existir microrganismos patogênicos que não foram inativados por meio da pasteurização. Têmse como medidas preventivas o controle do binômio tempo/temperatura do processo, a higienização do pasteurizador e demais utensílios envolvidos nesta etapa e padronização do leite.

$\mathrm{O}$ "tratamento térmico a $90{ }^{\circ} \mathrm{C}$ " constitui um PCC pela possibilidade de sobrevivência de bactérias termoresistentes e formadoras de esporos. As medidas preventivas incluem também o controle do binômio tempo/ temperatura e cuidados higiênico-sanitários No resfriamento a $40{ }^{\circ} \mathrm{C}$, o perigo biológico pode estar relacionado com a possível sobrevivência de bactérias mesófilas ou a uma recontaminação pós-pasteurização por falta e/ ou inadequado uso do programa de qualidade Boas Práticas de Fabricação.

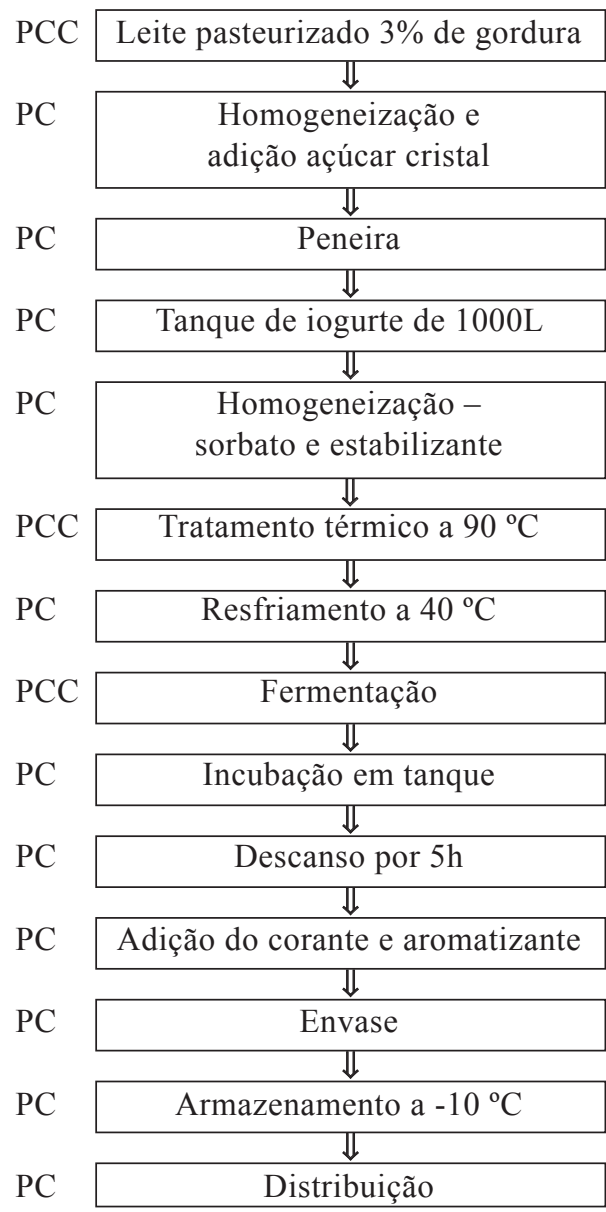

Figura 2 - Fluxograma de fabricação do iogurte sabor morango

A fermentação foi considerada PCC, pois durante o processo pode haver aumento excessivo da acidificação causada pelo acúmulo de ácido lático no leite e produção 
de outras substâncias secundárias que influenciam a característica sensorial do produto. Deve-se fazer o controle do tempo e da temperatura para a inoculação do fermento, além da higienização correta dos tanques de fermentação. Esse processo é realizado de acordo com a orientação do fabricante da cultura láctea, que sugere o tempo e temperatura de fermentação. Porém, como o fermento utilizado neste laticínio era composto por bactérias termofílicas, temperaturas de fermentação inferiores a $39^{\circ} \mathrm{C}$ não são recomendadas, por promoverem um desequilíbrio na proporção das bactérias que compõem o fermento, o que aumenta a possibilidade de pós-acidificação, sinerese e problemas de viscosidade.

Os principais Pontos de Controle (PC) observados foram: homogeneização e adição do açúcar cristal, homogeneização do sorbato e estabilizante, resfriamento a $40{ }^{\circ} \mathrm{C}$, incubação em tanque, descanso por $5 \mathrm{~h}$, adição do corante e aromatizante, envase, armazenamento a $-10{ }^{\circ} \mathrm{C}$ e distribuição.

Cuidados higiênico-sanitários são necessários nas etapas de "homogeneização e adição do açúcar cristal" e na "peneira", para evitar a presença de perigos de natureza física e possível adesão de microrganismos associados a procedimentos inadequados de higienização. O tanque de fermentação de iogurte deve ser de material apropriado como aço inoxidável, para facilitar o tratamento térmico e a higienização.

A etapa de "homogeneização do sorbato e do estabilizante" é importante para a textura e conservação do iogurte. O sorbato por ser ter característica ácida, possui atividade inibitória contra muitos fungos filamentosos e leveduras e bactérias, incluindo a maioria das bactérias patogênicas. Os estabilizantes favorecem e mantêm as características físicas das emulsões e suspensões, influenciando na viscosidade do iogurte. Esta etapa é considerada um PC, considerando que quando usados sem o devido controle e em desacordo com os limites máximos permitidos representam perigos de natureza química. O mesmo fato se dá na etapa de "adição de corantes e aromatizantes".

As etapas de inoculação do fermento em tanque e manutenção por 5 h, se não realizadas de forma correta, podem ocasionar um desbalanceamento do fermento, com aumento da possibilidade de pós-acidificação, sinerese e problemas de viscosidade. As etapas de "envase", "armazenamento do produto a - $10{ }^{\circ} \mathrm{C}$ " e "distribuição" se não realizadas com cuidados higiênico-sanitários e controle de tempo e de temperatura, pode levar a contaminações biológicas e físicas. Como medidas preventivas têm-se o controle da temperatura e do tempo de estocagem, além de procedimentos adequados de higienização.

\section{Resultado das análises microbiológicas do leite pasteurizado e do iogurte de morango}

As médias dos resultados das análises microbiológicas realizadas no leite pasteurizado padronizado a $3 \%$ de gordura e do iogurte de morango estão apresentadas na Tabela 2.

Os resultados das análises microbiológicas do leite pasteurizado e do iogurte de morango mostraram que não houve contaminações por nenhum dos microrganismos analisados, encontrando-se assim de acordo com a legislação vigente (ANVISA, 2001). A pasteurização tem como objetivo a inativação de microrganismos patogênicos e a redução significativa de deterioradores. A fermentação consiste na ação de bactérias ácido-láticas sobre açúcares, transformando-os em ácido lático e outros produtos secundários como aldeído, cetonas, álcoois, dentre outros, que contribuem para alterações de sabores e odores nos produtos finais. Como ocorre a acidificação do alimento, este se torna menos propicio ao desenvolvimento da maioria das bactérias (SANTOS; SIMM, 2011). 
Tabela 2 - Resultados das médias dos valores microbiológicos dos produtos elaborados

\begin{tabular}{c|c|c|c|c}
\hline \multirow{2}{*}{ Produtos } & \multicolumn{4}{|c}{ Análises Microbiológicas } \\
\cline { 2 - 5 } & $\begin{array}{c}\text { Coliformes } \\
\text { totais } \\
(\mathrm{NMP} / \mathrm{mL})\end{array}$ & $\begin{array}{c}\text { Coliformes } \\
\text { termotolerantes } \\
(\mathrm{NMP} / \mathrm{mL})\end{array}$ & $\begin{array}{c}\text { Staphylococcus } \\
\text { aureus } \\
(\mathrm{em} 25 \mathrm{~mL})\end{array}$ & $\begin{array}{c}\text { Salmonella } \text { ssp. } \\
(\mathrm{em} 25 \mathrm{~g})\end{array}$ \\
\hline Leite & $<3$ & $<3$ & $>10^{1}$ & Ausência \\
Iogurte & $<3$ & $<3$ & Ausência \\
\hline
\end{tabular}

*NMP: Números mais prováveis

Embora a legislação vigente não exija a análise de Staphylococcus aureus para os produtos estudados, esta análise foi realizada para fins de diagnóstico mais detalhado sobre as condições higiênico-sanitárias do processamento dos derivados.

Os resultados constatados assemelhamse aos observados por Souza (2010) que ao analisarem amostras de leite pasteurizado de diferentes marcas em Pelotas (RS) verificaram a sua adequação para o consumo humano. Santos; Simm (2011) também constataram a adequação de amostras de leite pasteurizado e iogurte coletadas no Pantanal Sul-MatoGrossense. Em contrapartida, Moura (2012) ao analisar 90 amostras de leite pasteurizado no Ceará e Silva et al. (2010) ao avaliaram 120 amostras de leite pasteurizado comercializados no Rio de Janeiro, detectaram a presença de coliformes totais e coliformes termotolerantes, com valores acima do permitido pela legislação vigente. Oliveira et al. (2013) avaliaram iogurtes de morango industrializados e comercializados em Linhares, ES, e verificaram que os produtos apresentaram contaminação com coliformes totais e termotolerantes, acima do permitido pela legislação.

\section{Avaliações microbiológicas das superfícies de processamento de produtos lácteos}

Não existem padrões microbiológicos na legislação brasileira para superfície de equipamentos e utensílios. Desta forma, foram usadas as especificações descritas pela APHA (2001) que recomenda contagens de coliformes termotolerantes inferiores a 50 $\mathrm{UFC} / \mathrm{cm}^{2}$ e ausência de patógenos, de acordo com Andrade (2008).

Não foram constatadas superfícies de equipamentos contaminadas por coliformes termotolerantes (Tabela 3). Em mãos de um manipulador constataram-se contagens de $11 \mathrm{NMP} / \mathrm{cm}^{2}$, ou seja, estava dentro do número aceitável (APHA, 2001; ANDRADE, 2008). Entretanto, a maioria das superfícies estava contaminada por coliformes totais, com contagens de $120 \mathrm{NMP} / \mathrm{cm}^{2}$, acima da especificação da APHA (2001). A única superfície em que não foi constatada a presença de coliformes totais foi a embalagem de polietileno, utilizada para o acondicionamento dos iogurtes (Tabela 3). Silva et al. (2011) ao avaliarem a qualidade microbiológica de equipamentos e utensílios de um laticínio em Minas Gerais, constataram que todas as amostras apresentaram níveis de coliformes totais e termotolerantes (contagens máximas de $5 \times 10^{5} \mathrm{NMP} / \mathrm{cm}^{2}$ ).

Todas as amostras de superfícies apresentaram-se contaminadas por Staphylococcus aureus (Tabela 3). A maior contagem foi observada nas mãos de um manipulador, que foi de $2,1 \times 10^{3} \mathrm{UFC} / \mathrm{cm}^{2}$. Já a menor contagem foi observada na superfície da embalagem de iogurte $\left(<10 \mathrm{UFC} / \mathrm{cm}^{2}\right)$. Silva et al. (2011) também verificaram contami 
nação por este microrganismo em superfícies de equipamentos e utensílios de laticínios em Minas Gerais, com níveis de 1,2 a 1,3 $\mathrm{x} 10^{2} \mathrm{UFC} / \mathrm{cm}^{2}$. Em contrapartida, Viana et al. (2013) avaliaram superfícies e mãos de manipuladores em laticínios do Paraná e verificaram que $56 \%$ das amostras de superfícies de equipamentos estiveram dentro dos padrões higiênicos recomendados e $53 \%$ das amostras de manipuladores foram consideradas satisfatórias, com até 100 UFC/mão.

A avaliação da eficiência dos procedimentos de higienização de equipamentos e utensílios é uma necessidade constante para fins de prevenção de contaminações dos alimentos (CAMPDEPADRÓS et al., 2012). Mãos avaliadas de três manipuladores do laticínio apresentaram condições inadequadas de higiene, que foi evidenciado por meio dos resultados das análises de Staphylococcus aureus, com os valores variando de 8,7 x $10^{2}$ a $2,1 \times 10^{3} \mathrm{UFC} /$ mão, além de algumas falhas identificadas durante a avaliação de
BPF. Segundo Andrade (2008), a presença deste microrganismo é indicadora de falhas higiênico-sanitárias de manipuladores, uma vez que esta bactéria é frequentemente encontrada na pele e nas fossas nasais e orais de pessoas saudáveis. Não há ainda especificações ou padrões na legislação brasileira quanto a contagem microbiana das mãos de manipuladores. De acordo com descrição de Andrade (2008) contagens microbianas inferiores a 1,5 x 10² UFC/mão são indicativas de condições higiênicas satisfatórias.

As médias dos resultados das análises microbiológicas realizadas nas superfícies envolvidas nos processos de elaboração dos produtos estão apresentadas na Tabela 3.

\section{CONCLUSÃO}

Por meio da aplicação da lista de verificação de BPF, o laticínio enquadrou-se no Grupo 1 ( $76 \%$ a $100 \%$ de conformidade), sendo classificado como "Bom". O item que

Tabela 3 - Média dos resultados das avaliações microbiológicas de superfícies de processamento e de embalagens do laticínio

\begin{tabular}{|c|c|c|c|}
\hline \multirow[b]{2}{*}{ Superfícies } & \multicolumn{3}{|c|}{ Análises Microbiológicas } \\
\hline & $\begin{array}{l}\text { Coliformes } \\
\text { totais } \\
\left(\mathrm{NMP} / \mathrm{cm}^{2}\right)\end{array}$ & $\begin{array}{c}\text { Coliformes } \\
\text { termotolerantes } \\
\left(\mathrm{NMP} / \mathrm{cm}^{2}\right)\end{array}$ & $\begin{array}{c}\text { Staphylococcus } \\
\text { aureus } \\
\left(\mathrm{UFC} / \mathrm{cm}^{2}\right)\end{array}$ \\
\hline Galão de transporte de leite & 35 & $<3$ & $4,2 \times 10$ \\
\hline Tanque de recepção de leite & 120 & $<3$ & $8,2 \times 10^{2}$ \\
\hline Esteira & 120 & $<3$ & $7,9 \times 10^{2}$ \\
\hline Bancada de envase do iogurte & 120 & $<3$ & $3,7 \times 10^{2}$ \\
\hline Fermenteira do iogurte & 120 & $<3$ & $9,6 \times 10^{2}$ \\
\hline Faca & 120 & $<3$ & $5,6 \times 10^{2}$ \\
\hline Peneira & 35 & $<3$ & $9,2 \times 10$ \\
\hline Mesa de aço inoxidável & 120 & $<3$ & $3,1 \times 10^{2}$ \\
\hline Embalagem de iogurte & $<3$ & $<3$ & $<10$ \\
\hline Manipulador 1 & 120 & 11 & $2,1 \times 10^{3}$ \\
\hline Manipulador 2 & 35 & $<3$ & $9,4 \times 10^{2}$ \\
\hline Manipulador 3 & 120 & $<3$ & $8,7 \times 10^{2}$ \\
\hline
\end{tabular}


apresentou maior percentagem de conformidade foi "Controle de Qualidade do Produto Final" e "Documentação", com um percentual de conformidade de $100 \%$. O item com menor percentual de adequação foi "Edificações e instalações" (81,84\%).

O estudo dos fluxogramas de processamento do leite pasteurizado padronizado a $3 \%$ de gordura e do iogurte de morango permitiu constatar perigos consideráveis à saúde dos consumidores além de identificar os Pontos Críticos de Controle (PCC) e Pontos de Controle (PC) em cada etapa do processo e medidas preventivas.

Por meio das análises microbiológicas dos produtos constatou-se a sua adequação à legislação vigente e ao consumo. Observou-se por meio da análise das superfícies adequação quanto ao índice de contaminação com coliformes termotolerantes, mas observou-se alto índice de contaminação por Staphylococcus aureus e coliformes totais. Esses resultados são indicativos da ocorrência de falhas nos procedimentos de higienização e manutenção dos utensílios e equipamentos.

\section{REFERÊNCIAS}

AGÊNCIA NACIONAL DE VIGILÂNCIA SANITÁRIA (ANVISA). Resolução de Diretoria Colegiada, $\mathrm{RDC} \mathrm{n}^{\circ} 12$, de 02 de janeiro de 2001. Aprova o Regulamento Técnico sobre padrões microbiológicos para alimentos. Diário Oficial da República Federativa do Brasil, Brasília, 10 jan. 2001.

\section{AGÊNCIA NACIONAL DE VIGILÂNCIA} SANITÁRIA (ANVISA). Resolução de Diretoria Colegiada, RDC n ${ }^{\circ} 275$, de 21 de outubro de 2002. Aprova o Regulamento Técnico sobre os procedimentos operacionais padronizados e a lista de verificação das boas práticas de fabricação em estabelecimentos produtores/Industrializadores de alimentos. Diário Oficial da República Federativa do Brasil, Brasília, 30 ago. 2002.
AGÊNCIA NACIONAL DE VIGILÂNCIA SANITÁRIA (ANVISA). Resolução de Diretoria Colegiada, RDC ${ }^{\circ} 216$, de 15 de setembro de 2004. Aprova o Regulamento Técnico de boas práticas para serviços de alimentação. Diário Oficial da República Federativa do Brasil, Brasília, 15 set. 2004.

ANDRADE, N. J. Higiene na Indústria de Alimentos. São Paulo: Varela, 2008. 412p.

APHA. American Public Health Association Compendium of Methods for the Microbiological Examination of Foods. $3^{\mathrm{a}}$ ed. Washington, DC: American Public Association, 2001. 1219p.

BRASIL, Ministério da Agricultura, Pecuária e Abastecimento. Portaria $n^{\circ} 368$, de 04 de setembro de 1997. Aprova o Regulamento Técnico sobre as Condições Higiênico Sanitárias e de Boas Práticas de Fabricação para Estabelecimentos Produtores/Industrializadores de Alimentos. Brasília, Diário Oficial da República Federativa do Brasil, 08 set. 1997.

CAMPDEPADRÓS, M. et al. Effectiveness of two sanitation procedures for decreasing the microbial contamination levels (including Listeria monocytogenes) on food contact and non-food contact surfaces in a dessertprocessing factory. Food Control, v. 23, p. 26-31, 2012.

EVANCHO, G. M et al. Microbiological monitoring of the food processing environment. In: DOWNES, P. F.; ITO, K. Compendium of methods for the microbiological examination of foods. Ed. Washington: American Public Health Association (APHA), 2001. p. 25-35.

FAO/WHO. Food Hygiene Basic Texts. $3^{\mathrm{a}}$ ed. Rome: FAO/WHO, 2003. 31p. 
FIGUEIREDO, E. L.; LOURENÇO JÚNIOR, J. B.; TORO, M. J. U. Caracterização físicoquímica e microbiológica do leite de búfala "in natura" produzido no Estado do Pará. Revista Brasileira de Tecnologia Agroindustrial, v. 04, n. 01, p.19-28, 2010.

MOURA, L. B. de. Análise microbiológica de leite pasteurizado tipo $\mathrm{C}$ destinado ao programa leite é saúde do Ceará. Revista Verde de Agroecologia e Desenvolvimento Sustentável, v. 7, n. 5, p. 85-90, 2012.

OLIVEIRA, F. M.; LYRA, I. N.; ESTEVES, G. S. G. Avaliação microbiológica e físico-química de iogurtes de morango industrializados e comercializados no município de Linhares - ES. Revista Brasileira de Produtos Agroindustriais, Campina Grande, v. 15, n. 2, p. 147-155, 2013.

PROGRAMA ALIMENTO SEGURO (PAS). SENAI. Disponível em: <http://www. alimentos.senai.br>. Acesso em: 10 ago. 2015.

SANTOS, L. C.; SIMM, E. M. Qualidade do leite pasteurizado tipo $\mathrm{C}$ padronizado, comercializado na cidade de Pará de Minas, MG. Higiene Alimentar, v. 25, n. 202-203, p. 87-91, 2011.
SILVA, R. et al. Pasteurized milk: efficiency of pasteurization and its microbiological conditions in Brazil. Foodborne Pathogens and Disease. v. 7, n. 2, p. 217-219, 2010.

SILVA, N. B. N. et al. Avaliação microbiológica de equipamentos e utensílios utilizados em laticínios da região de Rio Pomba - MG. Revista do Instituto de Laticínios Cândido Tostes, v. 66, n. 378, p. 5-10, 2011.

SOUZA, D. P. Avaliação da qualidade higiênico-sanitária do leite utilizado no restaurante escola da Universidade Federal de Pelotas. Revista HCPA, v. 30, p. 27-300, 2010.

VIANA, C. et al. Avaliação microbiológica de swabs de superfícies e mãos de manipuladores de laticínios encaminhados ao serviço de rotina do Lacoma, UFPR. In: Simpósio Paranaense dos Centros Mesorregionais de Excelência em Tecnologia de Leite, 2013, Londrina. Anais eletrônicos... Disponível em: <http://www.uel.br/laboratorios/inspecao/ portal/pages/arquivos/Cartilhas/Anais $\% 20$ do $\% 20 \% 20$ Simposio $\% 20$ Paranaense $\% 20$ dos $\% 20$ Centros $\% 20$ Mesorregionais $\% 20$ de $\% 20$ Excelencia $\% 20$ em $\% 20$ Tecnologia $\% 20$ do\%20Leite.pdf $>$ Acesso em: 13 mar. 2017. 